\title{
Research on Comprehensive Evaluation and Early-warning Management of College Students
}

\author{
Wenpeng Lu \\ School of Information, Qilu University of Technology, Jinan 250014, China \\ Iwp@qlu.edu.cn
}

\begin{abstract}
The paper summarizes existing problem in teaching management, which pays more attention to the management of student scores and ignores the comprehensive evaluation and early-warning management. The importance and significance to develop comprehensive evaluation and early-warning management system of college students are pointed out. The related analysis technologies are mentioned. At last, an architecture of comprehensive evaluation and early-warning management system is put forward.
\end{abstract}

Keywords: early-warning; comprehensive evaluation; student management; development predict.

\section{Introduction}

With the development of the information age, network teaching management system has been used widely in most colleges and universities. The emergence of network teaching management system has provided great convenience to the course selection, curriculum arrangement, score record and query for the teachers and students. But there are still some deficiencies in the existing network teaching management system.

From the point of view of score management, the existing teaching management system only provides the functions to record and query students score. This only focuses on the management of the student's test scores, which ignores the evaluation management of student's usual performance. From the perspective of learning evaluation, the existing teaching management system can output all student's score and rank. This only focuses on the result evaluation, which ignores the students learning process evaluation. From the point of view of users, the existing teaching management system mainly provides two roles, which are student and teacher. This ignores the role of parents, which is not good for parents to participate in the student's learning management. From the point of view of student management, the existing teaching management system can't forecast the trend of the development of the students according to the assessment of student performance, which lacks the early-warning management to the student. The existing teaching management system can only reflect one aspect of the student or part of the school management, it is difficult to evaluate and supervise student's comprehensive performance.

Facing the above problems in the existing teaching management system, it is very necessary to analyze and early-warn the performance of student with their comprehensive evaluation data.

\section{Significance in Theory and Practice}

\subsection{Theoretical Significance.}

The college student's comprehensive evaluation mechanism is an important area of the current higher education research. Many scholars have tried to study and found a set of college student's comprehensive evaluation system, which is suitable to the situation of our country [1]. The research on comprehensive evaluation and early-warning management of college students is benefit to clarify the relationship between the comprehensive evaluation indexes, correctly understand the importance of student evaluation, and build up the construction of early-warning system of college students. The research is advantageous to achieve the goals of school education. Besides, it is the foundation of student systematic and scientific management concept.

\subsection{Practical Significance.}

Aiming at comprehensive evaluation system of college students, the paper tries to do further theoretical and practical research. We expect that the research is helpful to the reform of college 
student's comprehensive evaluation system in China, promote students early-warning mechanism to play a more important role. This would be beneficial to cultivate more talents and inspire student struggle enthusiasm, help them grow up and improve the effectiveness of student assessment [2].

Higher education has entered the stage of popular education. In order to discover and solve the problems in student management, strengthen the pertinence and effectiveness of student management work and cultivate student to grow up and success, it is of great significance to establish early warning mechanism of student management[3]. At the same time, to establish early-warning education mechanism is an effective management way to carry out the follow-up education college student management, which is the requirement of student's ideological education work, student development, humanized management and family education.

\section{Analysis Technologies}

\subsection{Analytic Hierarchy Process.}

Analytic hierarchy process (AHP) is put forward formally in the 1970s. AHP is a combination of qualitative and quantitative, systematic and hierarchical analysis method. Because its effectiveness in dealing with complex decision problem, it quickly get the attention in the world. Its application involves economic planning and management, energy policy and allocation, behavioral science, military, transportation, agriculture, education, health, environment and other fields. The basic idea of analytic hierarchy process (AHP) to process a complex decision problem is similar with people.

\subsection{Regression Analysis Prediction Method.}

Regression analysis prediction method is to analyze the correlation among more than two independent variables and a dependent variable, establish a prediction model to forecast. When the relationship between independent variable and dependent variable is linear, it is known as linear regression analysis.

\subsection{Fuzzy technology.}

The concept of "fuzzy" is propose by L. A. Zadeh in 1965. Its core is to maximally simulate human thinking and reasoning function, to study many things without a clear boundary in the real world. Fuzzy technology adopts the idea and theory of fuzzy mathematics, which is mainly refers to a kind of engineering technology based on fuzzy set theory, probability distribution theory and fuzzy logic reasoning.

At present, fuzzy technology combined with other technology has been applied in various fields. In our research, we puts forward the method to predict student academic performance with fuzzy technology combined with linear regression method.

\section{Architecture of Comprehensive Evaluation and Early-warning Management}

In our design, comprehensive evaluation and early-warning management system of college students is composed with following child modules: basic information management, mutual evaluation between students, upload of index score and behavior, weight setting of early-warning architecture, comprehensive early-warning, statistical analysis, student self-warning evaluation, result query, system maintenance, et al.

\subsection{Module of Basic Information Management}

The module of basic information management is mainly responsible to record student performance and daily information, which provides basic data and foundation for early-warning management. The functions of the module include the management of the examination score, the management of rewards and punishments, and the management of student's attendance.

\subsection{Module of Mutual Evaluation between Students}

The module of mutual evaluation between students is responsible to collect mutual evaluation data between students. After the students login the system main interface, they can evaluate early-warning level for each classmate. Finally, for each student, his early-warning levels evaluated by his classmates are comprehensive treated, which are used to get a final early-warning level. This would provide a necessary reference basis for the future. 


\subsection{Module of Upload of Index Score and Behavior}

The functions of the module of upload of index score and behavior are two-fold. On one hand, according to acquisition requirements of index score and behavior, the counselor of each class collects information about student daily behaviors and the teacher of each curriculum summarizes student scores. All of them are uploaded to the system. On the other hand, there may be some items that can't be evaluated quantitatively. For this kind of items, the module allows the teacher to describe a student with a comment. Combing the grades of scores and usual behavior performance, the module can make a comprehensive early-warning assessment [4].

\subsection{Module of Weight Setting of Early-warning Architecture}

Module of weight setting of early-warning architecture is the basic of early-warning system. AHP (analytic hierarchy process) provides an important guarantee for weighting solution of the system, which is one of the key parts of a warning system. The function of the module contains the design of the early-warning system and weight setting of each factors.

\subsection{Module of Comprehensive Early-warning}

Module of comprehensive early-warning is the most important subsystem of comprehensive evaluation and early-warning management of college students, which is the ultimate goal of the research. Its functions include two-fold. One is the analysis and treatment of student comprehensive performance. The other is to determine the final warning level of each student.

\subsection{Module of Statistical Analysis}

The module of statistical analysis is responsible to analyze and display statistical data with all kinds of forms. After getting a final warning data, we can display early warning result with a bar chart so as to make the early-warning information more intuitive.

The functions of the module are as follow: check the result of early-warning; compare the similarities and differences between students between the daily performance indicators; compare the differences of each student in two semesters of one year. By comparing the changes of a student in two semesters, we can find the problems of a student more precisely.

\subsection{Module of Student self-Warning Evaluation}

Module of student self-warning evaluation is used to facilitate the students to warn themselves. According to self-evaluation, students can input the corresponding early-warning data, which would be as a reference for the final early-warning.

\subsection{Module of Result Query}

Module of result query provides query interface for users. The functions of the module include: the query of student comprehensive scores and warning level; the query of student mutual evaluation. The interface of result query can be provided to the students, teachers and parents, which is beneficial to the three parties jointly supervise and urge students to learn together.

\subsection{Module of System Maintenance}

Module of system maintenance provides the interface to manage the comprehensive evaluation and early-warning management system of college students. The functions of the module are as follows. One is the maintenance of user data. This function maintains registered user information. One is the maintenance of user roles. The user with different roles would be provided different privileges and avoid giving users too many permissions. Among all users, the administrator permissions is the highest. The last is system management. To register a new user, login, change passwords, and log out are included in the system management functions.

\section{Conclusion}

This paper summarizes the deficiency in current daily management of college students, points out the necessity and significance to research and develop comprehensive evaluation and early-warning management of college students. The related analysis technologies are summarized. At last, a feasible architecture of comprehensive evaluation and early-warning management of college students is given. This would be beneficial for the others to research more deeply. 


\section{Acknowledgments}

The research work is partially supported by the Project of Shandong Province Higher Educational Science and Technology Program (J12LN09, J10LG20) and the project of Natural Science Foundation of Shandong Province (ZR2011FQ038).

\section{References}

[1] X. Yang, Z. Xu, and Y. Sun, "Analysis of school precaution system and student cooperation undergraduate tutorial system," Journal of Jixi University, vol.16, pp.5-7, Jan 2016.

[2] X. Yang, "The exploration of student achievement early warning management mode in higher vocational colleges," Journal of Liaoning Higher Vocational, vol.16, pp.110-112, Sep 2014.

[3] G. Wang, "Research on current condition of early warning of student violating discipline in art college and countermeasures," Journal of Heilongjiang College of Education, vol.31, pp.15-16, Jul 2012.

[4] A. Yuan, N. Zhang, and H. Shen, "Construction and application of index system of academic warning evaluation for college student", Heilongjiang Researches on Higher Education, pp.79-83, May 2014. 